\title{
Mechanical and hydrologic basis for the rapid motion of a large tidewater glacier
} 2. Interpretation

\author{
Barclay Kamb, Hermann Engelhardt, Mark A. Fahnestock, ${ }^{1}$ and Neil Humphrey ${ }^{2}$ \\ Division of Geological and Planetary Sciences, California Institute of Technology, Pasadena \\ Mark Meier and Dan Stone \\ Institute of Arctic and Alpine Research and Department of Geological Sciences, University of Colorado, Boulder
}

\begin{abstract}
The data presented in part 1 of this paper (Meier et al., this issue) are here used to assess the role of water input/output, water storage, and basal water pressure in the rapid movement of Columbia Glacier, Alaska. Consistently high basal water pressures, mostly in the range from $300 \mathrm{kPa}$ below to $100 \mathrm{kPa}$ above the ice overburden pressure, are responsible in an overall way for the high glacier flow velocities $3.5-9 \mathrm{~m}$ $\left.\mathrm{d}^{-1}\right)$, which are due mainly to rapid basal sliding caused by the high water pressure. Diurnal fluctuation in basal water pressure is accompanied by fluctuation in sliding velocity in what appears to be a direct causal relation at the upglacier observation site. The water pressure fluctuation tracks the time-integrated water input (less a steady withdrawal), as expected for the diurnally fluctuating storage of water in the glacier far from the terminus. At the downglacier site, the situation is more complex. Diurnal peaks in water level, which are directly related to intraglacial water storage as well as to basal water pressure, are shifted forward in time by 4 hours, probably as a result of the effect of diurnal fluctuation in water output from the glacier, which affects the local water storage fluctuations near the terminus. Because of the forward shift in the basal water pressure peaks, which at the downglacier site lead the velocity peaks by 6 hours, a mechanical connection between water pressure and sliding there would have to involve a 6-hour (quarter period) delay. However, the nearly identical nature of the diurnal fluctuations in velocity at the two sites argues for a single, consistent control mechanism at both sites. The velocity variations in nondiurnal "speed-up events" caused by extra input of water on the longer timescale of several days are only obscurely if at all correlated with variations in basal water pressure but correlate well with water storage in the glacier. It appears that small variations in water pressure ( $\leq 100 \mathrm{kPa}$ ) sufficient to produce the observed velocity variations (15-30\%) are mostly masked by pressure fluctuations caused by spontaneous local reorganizations of the basal water conduit system on a spatial scale much smaller than the longitudinal coupling length over which basal water pressure is effectively averaged in determining the sliding velocity. At the achieved level of observation the clearest (though not complication free) control variable for the sliding velocity variations is basal water storage by cavitation at the glacier bed.
\end{abstract}

\section{Introduction}

Surging glaciers, many tidewater glaciers, and ice streams differ from normal glaciers in that they flow much more

\footnotetext{
${ }^{1}$ Now at NASA Goddand Space Flight Center, Greenbelt, Maryland.

${ }^{2}$ Now at Department of Geology and Geophysics, University of Wyoming, Laramie.
}

Copyright 1994 by the American Geophyoical Union.

Paper number 94JB00467.

0148-0227/94/94JB-00467\$05.00 rapidly, due to rapid sliding on the bed or rapid deformation of a layer of rock debris at the bed [Clarke, 1987]. The physical controls of these basal processes are complex and poorly understood. Theoretically, water at the bed should play a significant role [e.g., Paterson, 1981, pp. 123, 292; Iken, 1981; Fowler, 1987; Kamb, 1991], but few direct observations of its action have been made.

A field program in 1987, described in part 1 of this paper [Meier et al., this issue], sought to bring additional understanding to the subject by observing the relation of basal sliding to water input and basal water pressure in the rapidly moving lower reach of Columbia Glacier, Alaska. The basal water system was tapped and water pressure 
monitored in five boreholes at two sites, and the ice motion at these sites was measured with close time resolution. The sites are designated $\mathrm{km} 52$ and $\mathrm{km} 59$ according to their approximate longitudinal positions along the glacier, of total length $64 \mathrm{~km}$ in 1987 . The designation $\mathrm{km}$ refers to a longitudinal centerline coordinate, in kilometers, measured from the head of the glacier, as shown by Meier et al. [this issue, Figures 1 and 2]). To estimate water input to the glacier, measurements were made of precipitation, ice melt, and the rate of filling of an ice-marginal lake. Water output from a nearby secondary lobe of the glacier was measured as a proxy for the output of the main glacier, which was inaccessible to measurement. The methods of observation and the data resulting from the 53-day period of observation are presented by Meier et al. [this issue] (hereafter referred to as part 1) and summarized here in Figure 1. The letter designations $a, b, \cdots, i$ for the individual time series (rainfall, wind speed, etc.) are the same throughout parts 1 and 2, for ease of comparison.

The observations reveal the following features, which represent ice flow and water flow responses to external forcings on various time scales: (1) high ice flow velocities and high basal water pressures throughout the observation period, (2) ice flow speed-up events, each lasting about 3 days, at times of increased water input to the glacier, (3) extra slowdowns of ice flow, in which, after a speed-up event, the ice velocity drops to a level persistently lower than prior to the speed-up event, and (4) diumal fluctuation in water input, basal water pressure, water outflow, and ice flow velocity.

Part 2 endeavors to interpret the data in part 1 by seeking rational cause-effect relationships among the observed variables ice velocity, borehole water level, and water input/output. We start with the expectation, based on previous observations and theory, that the observed ice motion, resulting mainly from basal sliding, is an increasing function of the basal water pressure, in accordance with the mechanics of the sliding process; we also assume that external water input generates basal water pressure and water output in accordance with the functioning of a glacial water transport system (conduit system). These relationships could be time dependent, involving a time lag or phase shift between the water input forcing and the resulting response in terms of water pressure, ice motion, conduit geometry, water output, and water storage. Such time dependence may be recognizable from the behavior seen on the different observed timescales of forcing. Also, the input-response characteristics may vary along the length of the glacier, which may be seen in comparing the behavior at the two sites. The web of relationships just noted constitutes an outline for a general model of the input-response system of the glacier. In the data interpretation we endeavor to place the observational details into this model framework, modifying it as the data may require. It would be desirable to build this framework into a comprehensive quantitative model of the hydrologic and flow mechanical system of the glacier, but that is a large step that lies beyond the reach of the present paper.

\section{Glacier Flow on Seasonal Timescale}

On the theoretical and empirical bases given below, we argue that the continuously high ice velocities $\left(3.5-9 \mathrm{~m} \mathrm{~d}^{-1}\right)$ result from rapid basal sliding caused by the continuously high basal water pressures observed over the 50-day time frame of our data set.

In surging Variegated Glacier, 97\% of the rapid motion $\left(\sim 10 \mathrm{~m} \mathrm{~d}^{-1}\right)$ was the result of basal sliding rather than internal deformation of the ice mass [Kamb et al., 1985, Figure 6]. Consistent with this, in nonsurging Variegated Glacier, internal deformation and basal sliding make subequal contributions to the slow "normal" motion ( $\leq 0.5$ $\mathrm{m} \mathrm{d}^{-1}$ ) (H. Engelhardt and B. Kamb, unpublished data, 1993). Because the basal shear stresses in Variegated Glacier and Columbia Glacier appear to be comparable $(\sim 150 \mathrm{kPa})$, from standard gravitational calculations [Raymond, 1980], we can expect the internal deformation in the two glaciers to be of the same order of magnitude. Hence rapid basal sliding is required also in Columbia Glacier to account for the high surface velocities. Basal sliding velocities of at least $1.5 \mathrm{~m} \mathrm{~d}^{-1}$ at $\mathrm{km} 52$ and $3.0 \mathrm{~m}$ $\mathrm{d}^{-1}$ at $\mathbf{~ k m ~} 59$ are indicated by the measured variations in surface velocity, which cannot be caused by internal deformation on the short timescale involved.

Models of the basal sliding process with cavitation [Weertman, 1964; Lliboutry, 1968; Iken, 1981; Fowler, 1986, 1987] indicate that as the basal water pressure increases above the cavitation threshold the steady state basal sliding velocity under fixed basal shear stress should increase progressively, and it should increase without limit as the water pressure approaches the flotation pressure (ice overburden pressure). The borehole water level data (Figure 1, curves $\mathrm{h}$ and i), assumed to represent manometrically the basal water pressure as discussed in part 1 , imply water pressures on average close to the flotation pressure. This is indicated by the average values of effective pressure (flotation pressure minus basal water pressure) listed in Table 1, which contains also the estimated numerical values of flotation level and average water level (from Figure 1, curves $h$ and i) on which the effective pressure values are based. In addition to the overall averages over the $\sim 40$ - to 50-day periods of observation, average values are given for shorter periods, $\sim 10$ days in length, during which the persistently highest and lowest average water pressures occurred.

The effective pressures in Table 1 are distinctly lower than the average value $(400 \mathrm{kPa})$ measured over a 25 -day period in surging Variegated Glacier at a location where the average ice velocity was $10 \mathrm{~m} \mathrm{~d}^{-1}$ [Kamb et al., 1985, Figures 5 and 9]. If the immediate cause of rapid basal sliding in surge was the high basal water pressure (low effective pressure), as concluded by Kamb et al. [1985, p. 478], then the lower effective pressures in Columbia Glacier (Table 1) would seem quite adequate as the cause of rapid sliding of this tidewater glacier. For comparison, in Variegated Glacier when not in surge, moving about $0.5 \mathrm{~m}$ 

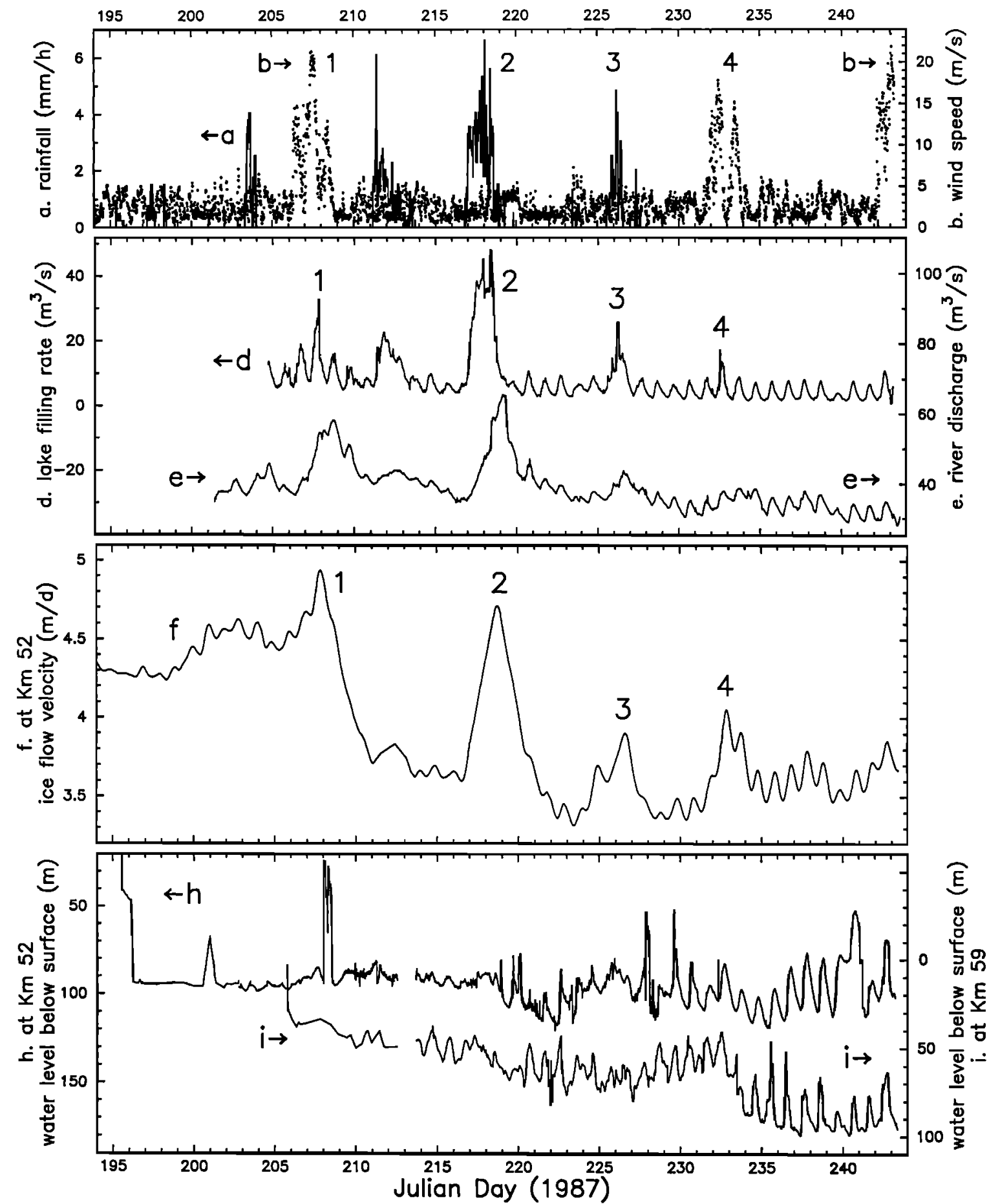

Figure 1. Summary of meteorological, hydrological, and glaciological data for Columbia Glacier during July 5, through August 31, 1987, from part 1: curves are a, rainfall (solid line); curve b, wind speed (dotted line); curve d, filling rate of a marginal glacial lake, which is a measure of water input to the glacier; curve e, discharge of outflow river from the East Lobe of Columbia Glacier, which may proxy for outflow from the glacier as a whole; curve $\mathrm{f}$, glacier flow velocity at $\mathrm{km} 52$, or, when multiplied by 1.8 , the flow at km 59 (part 1, Figure 5, curve g) to a good approximation; curve h, borehole water level depth at $\mathrm{km} \mathrm{52}$; and curve $i$, water level at $\mathrm{km} 59$. Variables are plotted as a function of time in Julian days (J.D.). Each tick mark is at 0000 hours UT (time of day) on the Julian day indicated by the numbering of the abscissa scale. The letter identifiers of the individual variables $(a, b, \ldots, i)$ are used consistently in the figures of parts 1 and 2 . Peaks corresponding to flow speed-up events are identified by numbers $1,2,3,4$. In curve $f$, the data gaps in Figure 5, curve $f$, part 1, have been bridged with cubic spline curves fitted to the data points at the ends of the gaps. Arrows indicate appropriate vertical scale. 
Table 1. Basal Effective Pressure Over Timescales $\sim 10$ Days, From Estimates of Flotation Level and Average Water Level Depth at Two Drill Sites

\begin{tabular}{lrrrrr}
\hline & \multicolumn{2}{c}{ Depth, $\mathrm{m}$} & & \multicolumn{2}{c}{ Effective Pressure, kPa } \\
\cline { 2 - 3 } \cline { 5 - 6 } & $\mathrm{km} 52$ & $\mathrm{~km} 59$ & & $\mathbf{k m ~} 52$ & $\mathbf{k m ~ 5 9}$ \\
\hline Flotation level (part 1, section 7) & $86 \pm 4$ & $56 \pm 7$ & & - \\
Average water level over observation period* & $96 \pm 4$ & $65 \pm 5$ & & $100 \pm 60$ & $90 \pm 90$ \\
Highest sustained water level* & $90 \pm 2$ & $49 \pm 5$ & & $40 \pm 40$ & $70 \pm 90$ \\
Lowest sustained water level* & $105 \pm 3$ & $88 \pm 2$ & & $190 \pm 50$ & $320 \pm 70$ \\
\hline
\end{tabular}

Depths are in meters below surface; drill sites are at $\mathrm{km} 52$ and $\mathrm{km} 59$.

*Time duration of sustained water levels and observation period (in days): observation period, 48 and 38; highest sustained level, 12 and 9; and lowest sustained level, 3 and 10.

$\mathrm{d}^{-1}$, summertime effective pressures averaged about $800 \mathrm{kPa}$ [Kamb and Engelhardt, 1987, p. 34]. In Findelen Glacier (Switzerland), moving at a similar velocity, the effective pressure over a 34-day period in May-June 1982 averaged about $500 \mathrm{kPa}$ [Iken and Bindschadler, 1986, Figure 2b]. For these glaciers there would appear to be a threshold at an effective pressure of about $450 \mathrm{kPa}$ between normal flow and surging or "continuously surging" flow.

What is responsible for the high basal water pressure that causes the rapid ice motion? The near-flotation pressure condition of Columbia Glacier 5-12 km upstream from its terminus is linked via the water conduit system to the nearflotation condition at the terminus of this tidewater glacier (part 1, section 2). However, it requires also a significant gradient of hydraulic head in the conduit system, because the flotation level was about $80 \mathrm{~m}$ above sea level at $\mathrm{km} 59$ and about $320 \mathrm{~m}$ above sea level at $\mathrm{km} 52$. The head gradient must be maintained by water flow in the conduit system, and a constraint on the nature of the conduit system is thus provided by these data.

If the ice velocities are directly controlled by water pressure, then there is seasonally an inverse relation between water pressure and water flow in the conduit system, because the ice velocities increase during late fall and winter when water flow decreases, and they decrease during late spring and summer when water flow increases [Meier et al., 1985]. This inverse relation suggests that the basal water system is of tunnel type, according to the model of Röthlisberger [1972]. Part of the summertime decrease in flow velocity is seen in Figure 1 (curve $f$ ), although the decrease is rather irregular and stepwise. Part of the presumed decrease in basal water pressure seems to be shown by the water level curve of Figure 1 (curve i), but this identification is called into question by the lack of any consistent decrease in Figure 1 (record h). These complications, and modeling of the basal water system by Fahnestock [1991, p. 75], cast doubt on the straightforward applicability of the tunnel conduit model.

From the tunnel conduit model, Bindschadler [1983, Figure 2] calculated effective pressures ranging from unspecified negative values to $+450 \mathrm{kPa}$ for the terminal

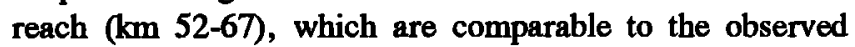
effective pressures (Table 1). He concluded that high basal water pressure was responsible for the rapid glacier motion.

At the level of accuracy estimated for the effective pressure values in Table 1, the one small negative value does not pose a particular problem. However, persistence of an actual negative value over a time long enough for vertical readjustments would result in the affected part of the glacier being floated off its bed, creating a gap between ice and bed. No indication of such a gap was encountered in the drilling operations, and the bending of the drill stem at the bottom of hole U-2 showed conclusively that there was no substantial gap at $\mathrm{km} 52$ [Humphrey et al., 1993].

\section{Speed-Up and Extra Slowdown Events}

If high basal water pressure acting over timescales $\geq 50$ days is responsible for the rapid motion of Columbia Glacier as argued above, we would expect to find a relation between borehole water level and ice velocity on shorter timescales, such as the relations seen in the surge and minisurges of Variegated Glacier [Kamb et al., 1985, p. 474; Kamb and Engelhardt, 1987, Figure 20], in the minisurges of Findelen Glacier [Iken and Bindschadler, 1986], and in a slowdown event on the Gorner Glacier [Röthlisberger and Lang, 1987, p. 273]. In fact, a definite relation of this kind is not recognizable in the Columbia Glacier data, as discussed below. This poses a major dilemma in interpreting the results of the study.

The ice flow velocity and water level records (Figures 1f, 1h, and 1i) show complicated fluctuations diurnally and on the timescale of the speed-up/extra-slowdown events $(\sim 3$ days). We first discuss the latter fluctuations, which are brought out by performing a 24-hour running average on the data (Figure 2), effectively filtering out the diumal fluctuations.

A cause-effect relationship between basal water pressure and sliding velocity should make itself evident as a correlation between fluctuations of water level and ice velocity seen in Figure 2 (curves $f$ and $h$, for $\mathbf{k m ~ 5 2 ) ~ a n d ~}$ Figure 2 (curves $\mathrm{g}$ and $\mathrm{i}$, for $\mathrm{km} \mathrm{59}$ ). In the early part of the time series there is a strong correlation between the velocity peak of speed-up event 1 and a high water level peak at $\mathrm{km} 52$ (but not $\mathrm{km} \mathrm{59)}$ on J.D. 208; also, a smaller water level peak on J.D. 201 correlates with the early part of a minor speed-up event (not numbered in Figure 2). Thereafter, however, correlation between velocity fluctuations and water-level fluctuations in Figure 2 is mostly poor or nonexistent.

Although the water level peak at the time of event 1 is impressive, it commenced 5 hours after the velocity peak 

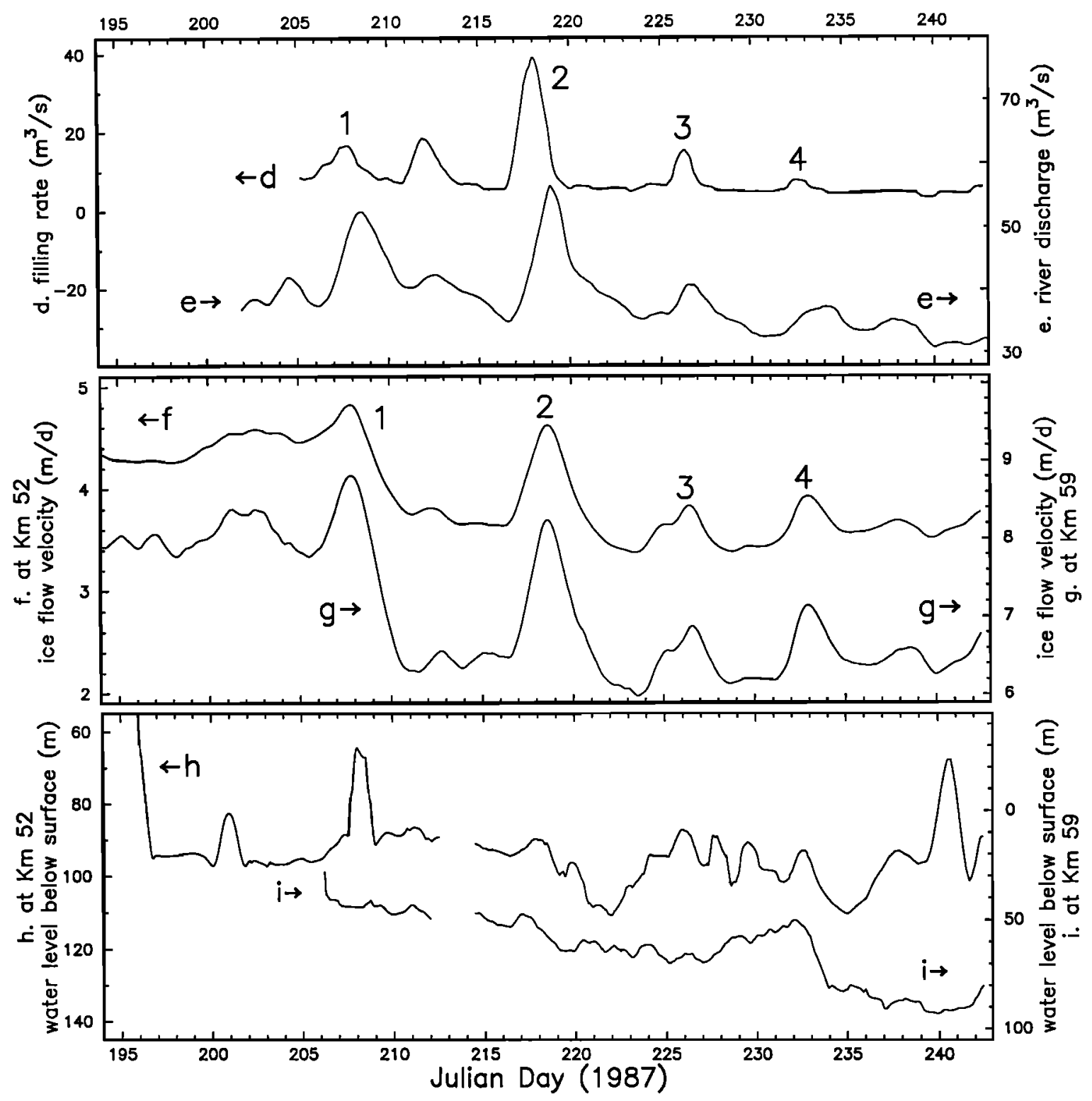

Figure 2. The 24-hour running average of data in Figure 1: curve d, lake filling rate; curve e, outflow river discharge; curve f, glacier flow velocity at $\mathrm{km} \mathrm{52}$; curve $\mathrm{g}$, glacier

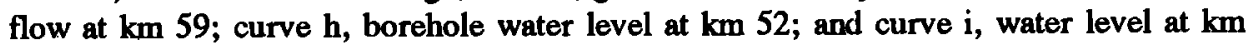
59. Arrows indicate appropriate vertical scale.

reached its maximum and was considerably shorter and sharper than the velocity peak, being in fact a double peak made up of two sharp spikes, each about 5.5 hours long (Figure 1 (curve h), or Figure 7 (curve U-3) of part 1). These details, which are not reflected in the velocity record, plus the fact that such a peak did not occur in association with the other speed-up events, casts doubt on the peak's significance for a systematic cause-effect relation between water pressure and sliding velocity in the speed-up events.

The extra-slowdown events show no better correlation between water level and ice velocity than do the speed-up events. The extra slowdown following event 2 was accompanied by a definite decrease in water level at $\mathrm{km} \mathbf{5 2}$, from a depth of about $90 \mathrm{~m}$ before the event to about $110 \mathrm{~m}$ afterward, and a less definite decrease at $\mathrm{km} 59$, from about $50 \mathrm{~m}$ to $60 \mathrm{~m}$ (Figure 2 (curves $\mathrm{h}$ and i)). However, in event 1 , for which the extra slowdown of velocity was much greater and more persistent, no overall decrease in water level was observed. A prominent overall decrease in water level occurred on J.D. 232-234, following event 4, especially at $\mathbf{k m} 59$, but this event was not accompanied by an extra slowdown.

An additional example of the lack of pressure-velocity correlation is provided by the $\sim 10$-day averages of sustained high and low water level listed in Table 1; they show no correlation with periods of sustained high and low ice velocity.

Before facing the dilemma posed by the lack of an observed cause-effect relation between basal water pressure and sliding velocity in the speed-up and extra-slowdown events, we first consider the hydrologic variables that do show clear cause-effect relations. 


\section{Relation of Stored Water to Speed-Up Events and Extra Slowdowns}

The diurnally filtered records (Figure 2) reemphasize the strong correlation between the velocity peaks of the speed-up events (numbered 1 to 4 in Figures 1 and 2) and peaks in water input (Figure 2, curve d) and water output (Figure 2, curve e), which was noted in part 1 , section 4 . The correlation is so good that there is no doubt that the extra input of water is responsible for the speed-ups.

However, the immediate cause-effect relation governing the sliding velocity is not a relation between it and the water input rate. This is shown by a definite violation of correlation between water input rate and ice velocity in the extra slowdowns: in both observed extra slowdowns, following events 1 and 2, the ice velocity dropped to a level distinctly lower than before the event, whereas the water input (and also output) returned after the event to essentially the same level as before the event. Walters and Dunlap [1987, p. 8975] noted the same thing for the extra slowdown observed in 1984. If the water input rate itself controlled the sliding rate, this violation of correlation would not occur.

A more subtle but similarly significant violation of direct correlation between water input (or output) and ice velocity is that in the speed-up events the velocity peak tends to lag behind the water input peak by about half a day, and the water output peak in turn lags behind the velocity peak by about half a day. Thus the water output peak lags the input peak by about a day. This can be seen in Figures 1 and 2 and is shown more clearly with the amplified time scale in Figure 3. (For event 1 the input (Figure 3a, curve d) leads the velocity peak by only 3 hours, but the wind speed peak (Figure 1, curve b), which is closely tied to enhanced water input from ice ablation (part I, section 4) leads by about 8 hours.) This lag of about 1 day is clearly visible for the speed-up events in Figures 1-3 and for the minor event on J.D. 211-212 in Figures 1 and 2.

The lag of the water output peak behind the input peak is an expression of the occurrence of extra storage of water in or under the glacier in connection with the events. Water storage is the time integral of the difference between water input and output rates. A peak in input rate accompanied by a percentagewise comparable peak in output rate that slightly lags the input peak corresponds to a peak in water storage that reaches its crest about midway in time between the input and output peaks (see section 6). This timing of the water

Figure 3. Expanded timescale plots of unfiltered data in time windows centered on the individual speed up events: (a) event 1; (b) event 2; (c) event 3; (d) event 4. Three data time series are plotted in each panel: time series $d$, lake filling rate; time series e, outflow river discharge; and time series $\mathrm{f}$, glacier flow velocity at $\mathbf{k m ~} 52$. The ordinate scales for time series $d$ and e are arbitrary but can be recovered from curves $d$ and $e$ in Figure 1. storage peak in each speed-up event, about halfway between input and output peak, is just the positioning of the ice velocity peak, as pointed out above. The velocity peak thus correlates distinctly better with the water storage peak than
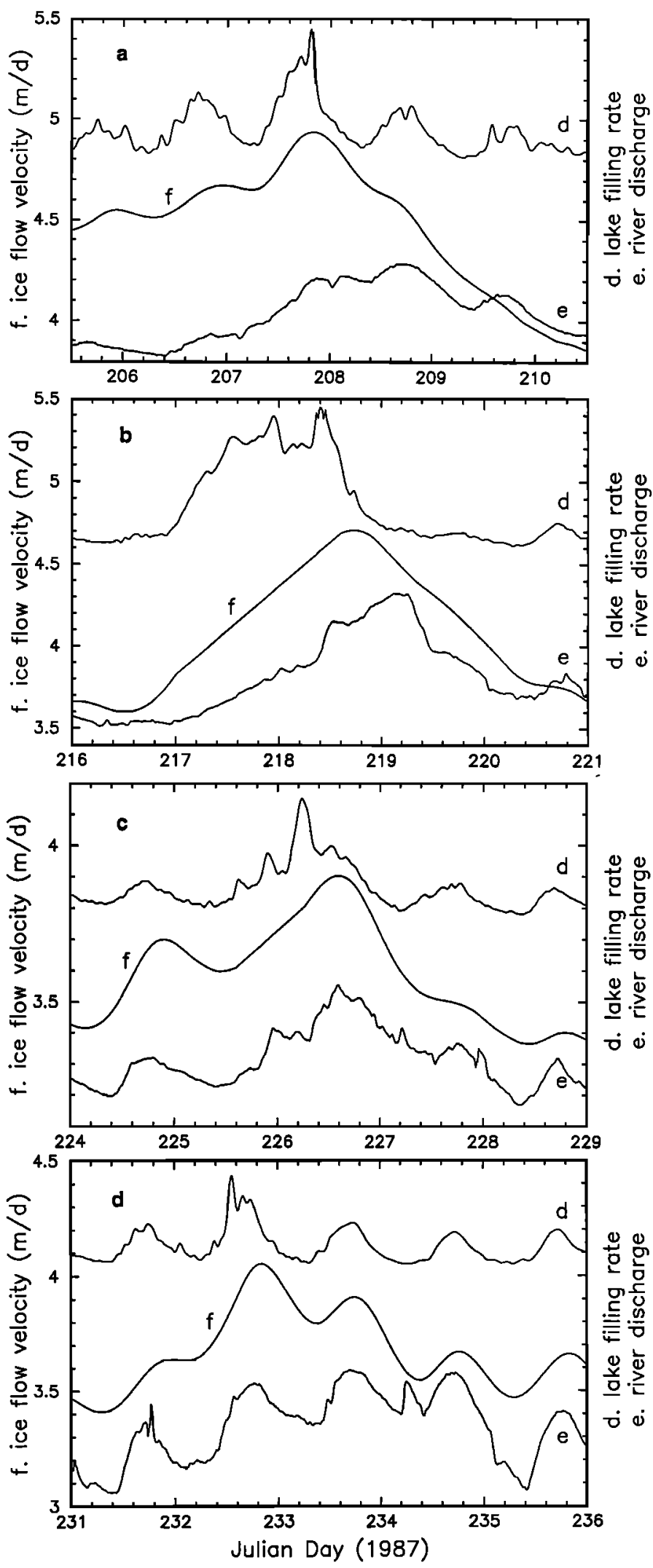
it does with either the water input or output peaks. This interpretation of the data is developed quantitatively by Fahnestock [1991]. We conclude that the variation in ice velocity in the speed-up events is directly controlled by water storage rather than by water input or output.

If a significant fraction of the extra water storage during the speed-up events is accommodated at the bed, the above conclusion accords with the often-made statement that meltwater "lubrication" of the bed is controlled by the amount of water at the bed, which reduces the ice-bedrock friction and promotes basal sliding [e.g,. Paterson, 1981, pp. 66, 124]. The evidence from Columbia Glacier does not distinguish between storage in a "water film" at the ice-bed interface [Weertman, 1972] or in water-filled basal cavities [Lliboutry, 1968].

The conclusion also accords with the observation that a considerable release of stored water from surging Variegated Glacier occurred in conjunction with major slowdowns in glacier motion [Kamb et al., 1985, p. 475]. The extra slowdowns of Columbia Glacier and the major slowdowns of surging Variegated Glacier appear to be very similar phenomena, although the latter were not clearly triggered by external water input events, as the former were. The quantitative interpretation by Fahnestock [1991] shows that the extra slowdowns in Columbia Glacier correlate with significant net loss of stored water. In the case of event 1 , which had the largest extra slowdown, the loss of stored water can be ascertained qualitatively from the relatively small size of the input peak and relatively large size of the output peak for this event (Figures 1-3).

\section{Control of Sliding by Areally Averaged Basal Water Pressure}

Basal cavitation models [Lliboutry, 1968; Iken, 1981; Fowler, 1986, 1987] reinforce physical intuition that an increase in basal water storage requires an increase in basal water pressure: the pressure drives the enlargement of basal cavities that store the water. Since fluctuations in basal sliding are directly controlled by water storage, as demonstrated above, why then do we not observe a clear cause-effect relation between fluctuations in basal water pressure and sliding velocity (section 3)?

To deal with this dilemma, we propose the following interpretation. In the control mechanism for basal sliding the influence of water pressure is effectively averaged over a large area of the bed, while fluctuations in water pressure occur quasi randomly within much smaller local subareas. Because of the averaging and the randomness, the local fluctuations can be much larger than the averaged, controlling pressure signal. In an individual borehole we see a local signal, in which the small controlling signal is obscured by the large local fluctuations. A small amplitude for the controlling pressure signal is to be expected, because a small increase in basal water pressure will have a large effect in increasing basal sliding and cavitation when the ambient pressure is close to flotation as it is here.

The averaging area should have dimensions of the order of the longitudinal coupling length $l$, the distance over which the basal-shear-stress/basal-sliding relation is effectively averaged in glacier flow [Kamb and Echelmeyer, 1986]. For the $\mathbf{k m ~ 5 2 - 5 9}$ reach of Columbia Glacier we estimate $l \sim 5 \mathrm{~km}$ from theory [Kamb and Echelmeyer, 1986, equations (19) and (23)]. For comparison, Walters [1989] calculated $l=2.7 \mathrm{~km}$ near the terminus, and this agreed approximately with $l=2.0 \mathrm{~km}$ evaluated from the upstream decay of the tidally forced semidiurnal flow velocity fluctuation (section 7 ). On this basis, the local subareas of the pressure fluctuations that are effectively averaged out in the sliding control process could be $\leq 100$ $m$ in size.

Some direct evidence for localization of basal water pressure subsystems is provided by the water levels in boreholes U-2 and U-3 during the period J.D. 198-202 when the two holes were both in operation (part 1, Figure 7). In hole U-3, which was located $280 \mathrm{~m}$ downstream from U-2, at a point where the ice surface was $6 \mathrm{~m}$ lower, the water level stood 14-19 $\mathrm{m}$ higher in elevation. If we accept the conclusion of part 1 , section 8, that $U-3$ was well connected to the basal water system, the difference in water level elevations indicates that the two holes tapped into separate pressure subsystems, separated by a hydraulic barrier. Another indication of separate subsystems is the fact that the water levels in the two holes did not rise and fall synchronously as they do in boreholes tapping a common pressure system [e.g., Hodge, 1976, Figure 9]. The lack of correlation between the water level records at $\mathrm{km} 52$ and 59 (Figures 2, curves $h$ and i) illustrates the independence of fluctuations in pressure subsystems $7 \mathrm{~km}$ apart. In nonsurging Variegated Glacier, two boreholes $100 \mathrm{~m}$ apart showed partially synchronous fluctuations, while boreholes 1.7 and $2.3 \mathrm{~km}$ apart showed fluctuations that were not correlated except for minisurge pulses [Kamb and Engelhardt, 1987, Figures 13 and 14].

What could cause the spatially localized pressure fluctuations? We surmise that the basal conduit system is capable of local reorganization, involving changes in the geometry of basal tunnels and cavities, opening or closing of basal ice fractures, and blocking or unblocking of conduits by rock or ice debris. Destruction of tunnels by advection against bedrock protuberances in the rapid sliding process is a likely cause of conduit reorganization. Local changes in the conduit system will cause fluctuations of basal water pressure as water flow through the system is locally impeded or facilitated in relation to the throughput and input fluxes handled by the system. Fluctuations of borehole water levels can in addition be caused by variations in the quality of connection between borehole and the basal water system (discussed in part 1 , section 8).

A special example of conduit reorganization is in surge termination when, according to Kamb [1987, p. 9098], a linked-cavity-type basal conduit system rapidly reorganizes into a tunnel system throughout the glacier. Major slowdowns during surge appear to be an incomplete form of such reorganization, perhaps on a more local scale, and partially reversible [Kamb et al., 1985, p. 479]. Extra external input of water is involved in triggering some reorganizations (as in the extra slowdowns), but others 
appear to occur spontaneously, as in minisurges and major slowdowns during surge.

Superimposed on the local pressure fluctuations generated in the above quasi random ways, according to the interpretation here proposed, are small but systematic, areally widespread pressure variations generated by water input to and outflow from the conduit system. Areal averaging of the pressure fluctuations recovers the small, systematic signal, which controls the sliding and cavitation and thus the basal water storage. This signal, expressed as a water level fluctuation, must have an amplitude $\leq 10 \mathrm{~m}$ to be effectively hidden by the fluctuation seen in Figure 2 (curves $h$ and $i$ ).

\section{Diurnal Fluctuations}

Diurnal fluctuations in ice velocity and borehole water level, which become particularly marked toward the end of the observation period (Figure 1), are doubtless a consequence of the diumal variation in water input that is indicated by the measurements of ice ablation and the Kadin Lake filling rate (Figure 4, curves $c$ and d). The welldeveloped diumal fluctuations in borehole water level, correlating strongly with the other variables (each with its own diurnal phasing), are in strong contrast with the poor correlation of water level with other variables at the longer time scales of speed-up and extra slowdown events (section 3). Thus the diurnal fluctuations present a distinctly different data set for interpretation in terms of cause-effect relations in the hydrologic and flow mechanical systems of the glacier. In relation to other glaciers for which diurnal fluctuations in velocity have been observed [e.g., Müller and Iken, 1973; Iken, 1972, 1978; Iken and Bindschadler, 1986], the record from Columbia Glacier is of special interest because of its completeness and detail. We attempt to interpret this record in terms of cause-effect relations based on the amplitude and phase relations among the variables.

Figure 4 shows the late-season diurnal fluctuations at an expanded timescale, during J.D. 226-243. Figure 5 gives the average profiles of the diurnal fluctuations during the time period of their most pronounced development, J.D. 230-243. Times of the averaged peaks and troughs in Figure 5 are listed in Table 2, together with means and standard deviations about the means for the individual peaks in Figure 4.

At $\mathbf{~ k m ~} 52$ the basal water pressure is in phase with the velocity fluctuation to within 1 hour (Table 2). This allows the velocity to be interpreted as a nearly immediate response to basal water pressure (with a 1-hour response lag). At $\mathbf{k m}$ 59 , on the other hand, the pressure leads the velocity by 6 hours (Table 2), so that, if there is a cause-effect relation between pressure and velocity, it involves a response lag of about 6 hours. The difference in response lag at the two sites may be connected with a difference in the extent of basal cavitation, related to the large difference in sliding velocity. The appearance of an observable cause-effect relation at diurnal period, when such a relation is not evident at the $\sim 6$-day period of the speed-up events (section 3 ), may perhaps be explained by reduced sensitivity of sliding and cavitation to pressure fluctuations at short period: if the basal cavity/tunnel system adjusts less to pressure fluctuations at shorter period, less fluctuating basal storage is produced, and therefore more of the fluctuation in input has to be accommodated by fluctuating intraglacial storage, which increases the water level fluctuation (see below). Reduced response sensitivity of sliding and cavitation to pressure fluctuations at short period is expected if there is a response inertia that slows the response.

An attempt to relate the diurnal water level and ice velocity fluctuations in detail to water input, output, and storage is subject to uncertainties as to the applicability of the proxy records of water input and output (Figures 4 (curves $c$ and $e$ ) and 5 (curves $c$ and e)). The 4-hour time difference between the peaks in ablation rate and Kadin Lake filling rate (Table 2, variables $c$ and d) suggests an uncertainty of this order in the phasing of the applicable water input fluctuation, which may be different at the two drill sites. Also uncertain is the extent to which the discharge from the East Lobe (Figures 4 (curve e) and 5 (curve e)) is representative of the fluctuation in output from the main glacier. The output fluctuations from the East Lobe are similar in phasing to those from valley glaciers [Elliston, 1973; Röthlisberger and Lang, 1987, pp. 225, 228, 273]; however, the output of a large tidewater glacier, with water conduit system well below sea level in its terminal reach, might possibly differ in significant ways. Also, the withdrawal of water from local storage near the individual sites may differ from the output of the glacier as a whole. Mindful of these uncertainties we discuss the implications of the hydrologic observations as they stand.

The diumal water output fluctuation, expressed as a percentage of the mean outflow (fluctuation half amplitude of $6 \%$, from Figure 5 , curve e), is very much smaller than the diurnal water input fluctuation (half amplitude $100 \%$ for ablation, Figure 5 , curve $c$, or $50 \%$ for lake filling rate, Figure 5, record d). This indicates that for the glacier taken as a whole there is a substantial diurnal fluctuation in water storage. (As noted in section 4, water storage is the time integral of the difference between the water input and output rates.) The magnitude of the storage fluctuation is fixed by the input fluctuation, because the output fluctuation is practically negligible percentagewise. Thus the glacierwide diumal water storage fluctuation is essentially the time integral of the "reduced input" (defined as the input reduced by a steady loss that balances on average the fluctuating input). We will refer to this integral as the cumulative reduced input (CRI). A measure of the CRI is the cumulative reduced ablation (CRA) shown in Figure 5, curve c'; it is the time integral of the average ablation curve (Figure 5, curve c) reduced by a constant so that its time average is 0 .

The diurnal fluctuation in ice velocity tracks the CRA fairly well (Figures 5, curves c', 5f, and 5g). Because the actual CRI probably lags the CRA somewhat, as the lake filling rate lags the ablation rate (Table 2), the velocity may be quite closely in phase with the CRI. This is compatible with the interpretation that water storage controls the sliding 

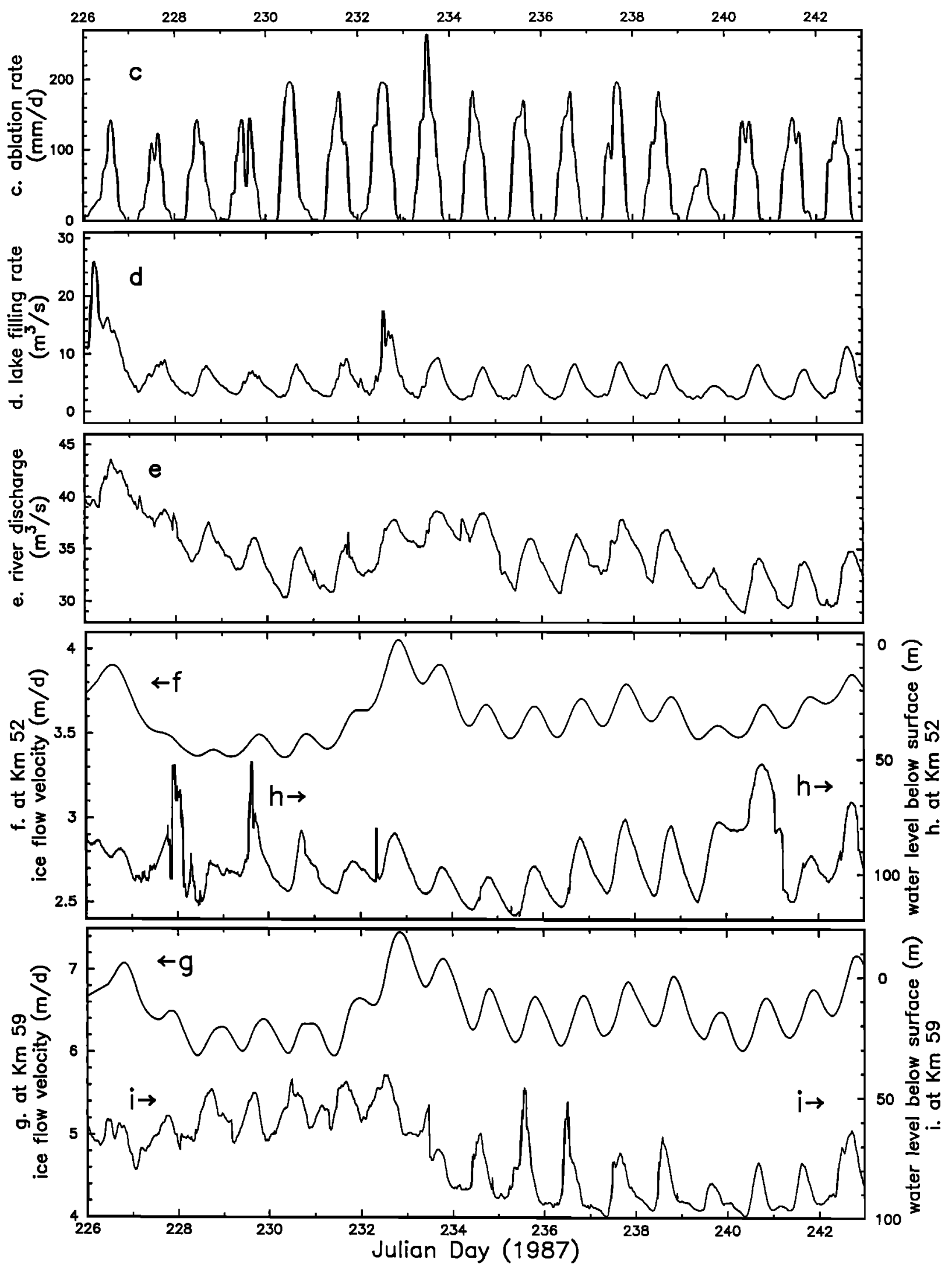

Figure 4. Expanded timescale plots of data in the time window J.D. 226-243, during which the diurnal fluctuations were best developed: curve $c$, ablation rate; curve d, lake filling rate; curve e, outflow river discharge; curve $f$, glacier flow velocity at $\mathrm{km} \mathrm{52}$;

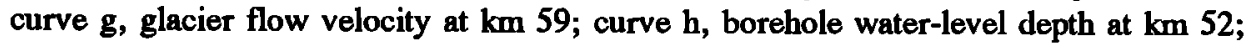
and curve i, water level at $\mathrm{km}$ 59. Arrows indicate appropriate vertical scale. 


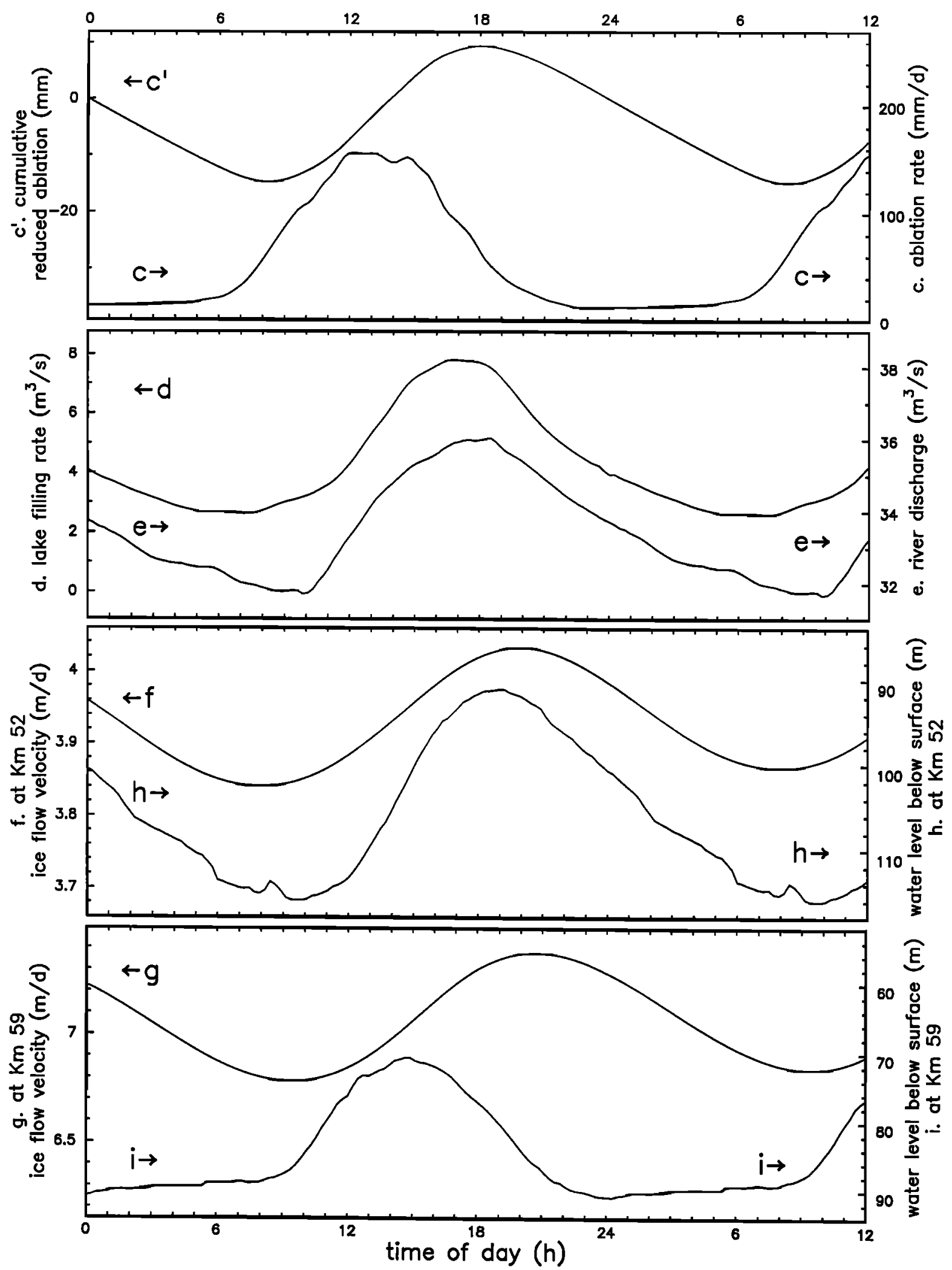

Figure 5. Averaged profiles of the diurnal fluctuations obtained by "stacking" the records over the time window J.D. 230-243: curve c, ablation rate; curve c', cumulative reduced ablation (see text, section 6); curve d, lake filling rate; curve e, outflow river discharge; curve f, glacier flow velocity at $\mathrm{km} 52$; curve $\mathrm{g}$, glacier flow velocity at $\mathbf{k m}$ 59; curve h, borehole water level depth at $\mathbf{k m ~ 5 2}$; and curve i, water level at $\mathbf{k m ~} 59$. Data are plotted versus time of day, in hours. The plot is continued cyclically from 24 hours ( $=0$ hour) on to $24+12$ hours, for better visibility of the wave forms. Arrows indicate appropriate vertical scale. 
Table 2. Diurnal Fluctuations: Average Time of Day of Peaks and Troughs

\begin{tabular}{|c|c|c|c|c|c|}
\hline & Variable & Peak"** & Peak $\dagger$ & Trough* & Trough $\dagger$ \\
\hline$\overline{\mathbf{c}}$ & ablation rate & 13.5 & $13.6 \pm 0.7$ & $01 \ddagger$ & - \\
\hline$c^{\prime}$ & cumulative reduced ablation (CRA) & 18 & - & 08 & - \\
\hline d & fill rate of Kadin Lake & 17 & $17.3 \pm 0.8$ & 07 & - \\
\hline e & discharge of Number One River & 18 & $17.7 \pm 0.5$ & 10 & $09.9 \pm 0.9$ \\
\hline f & velocity at $\mathbf{k m ~} 52$ & 20 & $19.4 \pm 0.8$ & 08 & $07.6 \pm 1.6$ \\
\hline g & velocity at $\mathbf{k m ~} 59$ & 21 & $20.6 \pm 1.0 \S$ & 09.5 & $09.3 \pm 1.4$ \\
\hline h & water level at $\mathrm{km} 52$ & 19 & $18.9 \pm 0.9$ & 10 & $09.8 \pm 0.7$ \\
\hline i & water level at $\mathrm{km} 59$ & 15 & $14.9 \pm 1.4 \|$ & - & - \\
\hline i & water level at $\mathrm{km} 59$ & - & $16.3 \pm 1.59$ & - & - \\
\hline
\end{tabular}

Time of day is given in hours.

*From records stacked over the interval J.D. 230-242 (Figure 5).

†Average time of daily peak (or trough) in time series (Figure 4) over the period J.D. 230-242, except as otherwise noted. The \pm figure is standard deviation of individual peaks or troughs about their means. Standard deviation of the mean is smaller by a factor of about $1 / 3$ (samples of about 10 data points).

$\ddagger$ Trough extends from about 22 hours to about 05 hours.

§Average over J.D. 220-242.

|| Average over J.D. 234-243.

AAverage over J.D. 214-224.

velocity, as discussed for the speed-up and extra-slowdown events in section 4.

A basis for the damping of output fluctuations relative to input fluctuations, and hence the appropriateness of the CRI as a measure of diurnally fluctuating water storage, is given by the following hydrologic model. Assume that the diumal timescale is too short for water pressure fluctuations to cause appreciable adjustments of conduits and basal cavities. The fluctuations in storage must then be accommodated intraglacially, in a porosity network to which both the surface water sources and the conduit system at depth have access. Assume that the porosity of this intraglacial storage system is areally uniform. Over wide areas of the glacier far from the terminus, a diurnally fluctuating input that is areally uniform would generate fluctuations in elevation but not in the slope of the intraglacial phreatic surface (upper surface of the stored water mass). Assume that the intraglacial storage system makes good hydraulic connection to the conduit system; then the level of the phreatic surface conforms manometrically to the basal water pressure. For areally uniform water input, then, the hydraulic gradient in the main conduits would remain unchanged, and, with no conduit adjustment, the water flow in the conduit system would remain unchanged. Thus the rate of withdrawal of water from any local area via the conduit system would remain unchanged. With steady output and fluctuating input, diurnal fluctuation in intraglacial water storage will take place as given by the CRI. The amplitude of fluctuation in elevation of the phreatic surface depends on the amplitude of the CRI and on the effective intraglacial porosity. (An effective porosity $1.1 \times 10^{-3}$ is indicated by the ratio of the fluctuation amplitudes of curves $c^{\prime}$ and $h$ in Figure 5.) If a borehole is well connected to the conduit system and thence to the intraglacial storage, the borehole water level provides an indication simultaneously of both the basal water pressure and the intraglacial storage. This model, as mentioned above, assumes that the timescale (hourly) is too short to permit spontaneous conduit adjustments; this assumption breaks down at longer timescales (days to months).

The situation at $\mathrm{km} 52,12 \mathrm{~km}$ from the terminus, appears to conform to the above model: the borehole water level tracks the CRI closely, especially if the CRI lags the CRA by about 1 hour.

In the above interpretation that the sliding velocity is controlled by water storage, the response presumably would be to basal storage, not to the intraglacial storage that is directly indicated by in the water level. This violates the model assumption of intraglacial storage only, but the model is easily amended to accommodate some diurnal fluctuation in basal storage as long as the assumption of no change in the water transport conduits is maintained.

What causes the water level peak at $\mathrm{km} 59(5 \mathrm{~km}$ from the terminus) to shift forward by 4 hours relative to the peak at $\mathrm{km} 52$ ? In the context of the foregoing hydrologic model, this shift is a logical consequence of the output fluctuation, which should have its largest effect on water storage near the terminus. Fluctuations in water level near the terminus are coupled to relatively large fluctuations in hydraulic gradient because the water level is fixed at sea level nearby; correspondingly, there will be relatively large fluctuations in water flux and flux gradient and therefore in withdrawal of water from local storage via the conduit system. This modifies the hydrologic model (fluctuating input, steady withdrawal) by subtracting a fluctuating withdrawal. If the amplitude of the fluctuation in local withdrawal rate is comparable to the amplitude of the input fluctuation, and if the withdrawal rate fluctuation is in phase with the observed 
fluctuation in output (Figure 5, curve e), the effect is to shift the local storage peak (and hence presumably the water level peak) forward to a time about halfway between the input and output peaks. (This is readily proven by integrating the input-minus-output function $\sin \omega t-\sin \omega(t-z)$, in which the input ( $\sin \omega t$ ) and output ( $\sin \omega(t-\tau)$ ) functions have unit amplitude and the output lags the input by the time lag $\tau$; the result of the integration can be expressed as $(2 / \omega) \sin 1 / 2 \omega \tau$ $\sin \omega(t-1 / 2 \tau)$, which is a sinusoidal storage curve with time lag $1 / 2 T$.) If the input is described by Figure 5 , curve $c$, and the output by Figure 5, curve e, peaks at 13.5 and 18 hours, respectively, and if the input and output fluctuation amplitudes are comparable as assumed above, then the storage peak should be at about 16 hours. This is close to the observed water level peak at 15 hours (Table 2).

The foregoing evaluation allows the fluctuations in water pressure and water outflow to be asynchronous, whereas synchroneity would be required in the model by the suggested control of outflow by the hydraulic gradient tied to sea level. The disparity could be overcome by assuming that the hydraulic conductivity of the conduit system has a delayed increase in response to water pressure, producing an outflow that lags the pressure. This assumption is closely related to the earlier assumption of a delayed velocity response to pressure at $\mathrm{km} 59$ and to the further assumption that basal storage lags pressure and intraglacial storage there, which would be needed if basal storage is in direct control of sliding.

There is a very strong similarity of the diurnal fluctuations in velocity at the two sites (Figures 4 (curves $f$ and $g$ ) and 5 (curves $f$ and $g$ ): the velocity fluctuation at $\mathbf{k m}$ 59 is to a good approximation the fluctuation at $\mathbf{k m ~} 52$ multiplied by the factor 3.0. (Compare with the scale-up factor 1.8 for the diumally averaged velocities.) This strong similarity does not argue for a complicated local control mechanism like the one discussed above for $\mathrm{km} 59$. It seems doubtful that a complicated mechanism that first shifts the water pressure peak forward in time and then causes the velocity peak to lag the pressure peak could result in a velocity fluctuation that is so little changed in shape from the fluctuation at $\mathrm{km} \mathrm{52}$, where these complications do not enter. The complications in the interpretation could be avoided by ascribing the velocity fluctuations at both sites directly to the CRI, which could be the same at both sites. However, the complicated hydrologic interpretation is still needed to deal with the role of water outflow (withdrawal) in affecting local water storage, and with the forward shift in the water level peak at $\mathrm{km} \mathrm{59.} \mathrm{Also,} \mathrm{there} \mathrm{is} \mathrm{no} \mathrm{evident}$ physical basis for ascribing the velocity fluctuations to the CRI alone, without influence from other factors.

The foregoing interpretations do not explain the special, distinctly nonsinusoidal shape of the water level curve at $\mathbf{k m}$ 59 (Figures 4 (curve i) and Figure 5 (curve i)), which somewhat resembles the ablation rate curve (Figure 5, curve c), with similarity in phasing (peaks at 15 and 13.5 hours). This relationship could be understood if the local intraglacial porosity at $\mathbf{k m ~} 59$ were quite low, so that the water level would rise immediately to a level linked directly to the local water input rate by the condition that the input be immediately conducted away via the basal water system. This interpretation could be extended to $\mathbf{k m ~} 52$ if the water input there were given by the lake-filling rate (Figure 5, record d), which peaks only 2 hours before the water level there (Table 2). However, there is no reason to think that the intraglacial porosity is low, especially at $\mathrm{km} 59$, where the extent of crevassing is extreme.

\section{Higher-Frequency Fluctuations}

In contrast to the dominant effect of the ocean tides in causing a semidiurnal fluctuation in ice flow velocity near the terminus of Columbia Glacier [Krimmel and Vaughn, 1987, Figure 7], almost no trace of such a fluctuation is seen at $\mathrm{km} 59$ and none at $\mathrm{km} 52$. At $\mathrm{km} 59,5 \mathrm{~km}$ above the terminus, there are possible weak semidiurnal peaks on J.D. $191,193,215,220$, and 222 (part 1, Figure 5, curve g). This is consistent with upstream decay in the semidiumal signal, which was observed by Krimmel and Vaughn [1987] and interpreted by Walters [1989] as noted in section 5 . The water level fluctuations also show no clear semidiumal signal, except at $\mathbf{k m ~} 59$ during J.D. 239-242, when weak but definite semidiurnal peaks intervene between the large diurnal peaks (Figure 4, curve i). The peaks are approximately in phase with the tidal peaks and could be caused by the fluctuation in tidal level, acting as a timevarying "base level" for the basal water pressure. However, it is not clear, within the rather low accuracy of observation of the peak timing, that the candidate semidiurnal peaks lag in time by about $50 \mathrm{~min}$ from one day to the next, as they would in a tidal signal (lunar semidiurnal period 12.42 hours). The diurnal fluctuations definitely do not show this progressive time lag and therefore do not have a predominantly tidal origin.

Frequency components higher than semidiurnal are evident in the water level records prior to about J.D. 230, but not in the velocity records (Figure 1) which may be due at least in part to the smoothing of the EDM data used in calculating the velocity (part 1, section 3). High frequencies are particularly prominent in the water level record from $\mathrm{km} 52$ during J.D. 210-230 (part 1, Figures 5 (curve h) and 7). The cause of the high-frequency fluctuations is not known. They could be due to rapid local reorganizations of the basal water system, similar to but more rapid than the reorganizations hypothesized in section 5 , or they could be due to rapid variations in the connection pathway between borehole and basal water system, which might be caused by the sliding of the basal ice over smallscale irregularities in the bed.

\section{Conclusions}

Although the observations support the conclusion that rapid sliding velocities are caused by high basal water pressures, near flotation, they do not provide a detailed relationship between pressure and sliding, either in connection with the speed-up and extra-slowdown events on time scales of several days or in connection with the welldeveloped diurnal fluctuations. 
At the longer timescale we attribute this shortcoming in the results to masking of the significant pressure signal by pressure fluctuation noise due to spontaneous local reorganizations of the basal water system. The noise has little or no effect on sliding because its influence is averaged out spatially in the process by which the sliding velocity is determined, which involves averaging of the controlling variables over an area of the bed with dimensions of the order of the longitudinal coupling length (a few kilometers).

A relation between sliding velocity and water storage in the glacier is definitely recognizable and is compatible with the foregoing model.

At the diurnal timescale, a simple relation between sliding and basal water pressure or, equally well, between sliding and water storage, would seem to be recognizable, if the data at $\mathrm{km} 52$ were fully representative of the glacier. However, the data at $\mathbf{k m ~} 59$ require complications in the simple hydrologic and mechanical model, involving phase delays in the response of basal sliding and cavitation to water pressure and involving the effect of water output on the water level fluctuation. The necessity for invoking these complications seems curious in view of the great similarity of the diumal fluctuations in sliding at the two sites.

More extensive measurements of borehole water levels and ice velocities in conjunction with the hydrologic variables will be necessary before the questions raised by this interpretation can be answered.

Acknowledgments. This work was supported by NSF grants DPP-8619348 and DPP-8619352.

\section{References}

Bindschadler, R., The importance of pressurized subglacial water in separation and sliding at the glacier bed, $J$. Glaciol., 29, 3-19, 1983.

Clarke, G.K.C., Fast glacier flow: Ice streams, surging, and tidewater glaciers, J. Geophys. Res., 92, 8835-8841, 1987.

Elliston, G.R., Water movements through the Gorner, LAHS Publ., 95, 79-84, 1973.

Fahnestock, M.A., Hydrologic control of sliding velocity in two Alaskan glaciers: Observation and theory, Ph.D. thesis, Calif. Inst. of Technol., Pasadena, 1991.

Fowler, A.C., A sliding law for glaciers of constant viscosity in the presence of subglacial cavitation, Proc. $R$. Soc. London A, 407, 147-170, 1986.

Fowler, A.C., Sliding with cavity formation, J. Glaciol., 33, 255-267, 1987.

Hodge, S.M., Direct measurement of basal water pressures: A pilot study, J. Glaciol., 16, 205-218, 1976.

Humphrey, N., B. Kamb, M. Fahnestock, and H. Engel hardt, Physical characteristics of the bed of the lower Columbia Glacier, Alaska, J. Geophys. Res., 98, 837846, 1993.

Iken, A., Measurements of water pressure in moulins as part of a movement study of the White Glacier, Axel Heiberg Island, J. Glaciol., 11, 53-58, 1972.

Iken, A., Variations of surface velocities of some Alpine glaciers measured at intervals of a few hours. Comparison with arctic glaciers, Z. Gletscherkd. Glazialgeol., 13, 23-35, 1978.

Iken, A., The effect of subglacial water pressure on the sliding velocity of a glacier in an idealized numerical model, J. Glaciol., 27, 407-422, 1981.

Iken, A., and R.A. Bindschadler, Combined measurements of subglacial water pressure and surface velocity of Findelengletscher, Switzerland: Conclusions about drainage system and sliding mechanism, J. Glaciol., 32, 101-119, 1986.

Kamb, B., Sliding motion of glaciers: Theory and observation, Rev. Geophys., 8, 673-728, 1970.

Kamb, B., Glacier surge mechanism based on linked cavity configuration of the basal water system, J. Geophys. Res., 92, 9083-9100, 1987.

Kamb, B., Glacier flow modeling, in Flow and Creep in the Solar System: Observations, Modeling, and Theory, edited by D.B. Stone and S.K. Runcorn, NATO ASI Series, 319, 417-506, 1991.

Kamb, B., and K.A. Echelmeyer, Stress-gradient coupling in glacier flow, I, Longitudinal averaging of the influence of ice thickness and surface slope, J. Glaciol., 32, 267 284, 1986.

Kamb, B., and H. Engelhardt, Waves of accelerated motion in a glacier approaching surge: The mini-surges of Variegated Glacier, Alaska, J. Glaciol., 33, 27-46, 1987.

Kamb, B., C.F. Raymond, W.D. Harrison, H. Engelhardt, K.A. Echelmeyer, N. Humphrey, M.M. Brugman, and T. Pfeffer, Glacier surge mechanism: 1982-1983 surge of Variegated Glacier, Alaska, Science, 227, 469-479, 1985.

Krimmel, R.M., and B.H. Vaughn, Columbia Glacier, Alaska: Changes in velocity, 1977-1986, J. Geophys. Res., 92, 8961-8968, 1987.

Lliboutry, L., General theory of subglacial cavitation and sliding of temperate glaciers, J. Glaciol, 7, 21-58, 1968.

Meier, M.F., L.A. Rasmussen, R.M. Krimmel, R.W. Olsen, and D. Frank, Photogrammetric determination of surface altitude, terminus position, and ice velocity of Columbia Glacier, Alaska, U.S. Geol. Surv. Prof. Pap., 1258-F, 1985.

Müller, F., and A. Iken, Velocity fluctuations and water regime of arctic valley glaciers, Int. Assoc. Hydrol. Sci. Publ., 95, 165-188, 1973.

Paterson, W.S.B., The Physics of Glaciers, p. 103, Pergamon, New York, 1981.

Raymond, C.F., Temperate valley glaciers, in Dynamics of Snow and Ice Masses, edited by S.C. Colbeck, pp. 80140, Academic, San Diego, Calif., 1980.

Röthlisberger, H., Water pressure in intra- and subglacial channels, J. Glaciol., 11, 177-203, 1972.

Röthlisberger, H., and H. Lang, Glacial hydrology, in Glacio-fluvial Sediment Transfer, edited by A.M. Gurnell and M.J. Clark, pp. 207-284, John Wiley, New York, 1987.

Walters, R.A., Small-amplitude, short-period variations in the speed of a tidewater glacier in south-central Alaska, U.S.A., Ann. Glaciol., 12, 187-191, 1989.

Walters, R.A., and W.W. Dunlap, Analysis of time series 
of glacier speed: Columbia Glacier, Alaska, J. Geophys. Res., 92, 8969-8975, 1987.

Weertman, J., The theory of glacier sliding, J. Glaciol., 5, 287-304, 1964.

Weertman, J., General theory of water flow at the base of a glacier or ice sheet, Rev. Geophys., 10, 287-333, 1972.

H. Engelhardt and B. Kamb, Divison of Geological and Planetary Sciences, California Institute of Technology, Pasadena, CA 91125.

M.A. Fahnestock, NASA Goddard Space Flight Center, MC 971, Greenbelt, MD 20771.
N. Humphrey, Department of Geology/Geophysics, Geology Bldg., Room 122, University of Wyoming, P.O. Box 3006, Laramie, WY 82071.

M.F. Meier and D. Stone, Institute of Arctic and Alpine Research and Department of Geological Sciences, Univ. of Colorado, Boulder, CO 80309-0450. (e-mail: meier_m @cubldr.colorado.edu; dstone@spot.colorado.edu).

(Received June 16, 1993; revised January 28, 1993; accepted February 11, 1994.) 